\title{
O USO DE EMOTICONS NAS FANPAGES DE FOLHA DE S.PAULO E ESTADÃO
}

\author{
Carlos Renan Samuel Sanchotene ${ }^{1}$
}

\begin{abstract}
Resumo: Neste artigo discutimos os modos como as lógicas das redes sociais alteram a narratividade jornalística. O uso de emoticons nas fanpages dos jornais Folha de S.Paulo e Estadão no Facebook foram analisados a fim de compreender como esse tipo de recurso textual é apropriado pelos veículos. Entre os resultados, destacamos que os emoticons promovem um aspecto mais informal ao conteúdo noticioso e mais próximo da linguagem dos leitores inseridos nas dinâmicas das redes sociais digitais.
\end{abstract}

Palavras-chave: Emoticons, jornalismo, redes sociais digitais, Facebook.

\begin{abstract}
This paper discusses the ways in which logic of social networks change the journalistic narrative. The use of emoticons in fanpages of Folha de S.Paulo and Estadão were analyzed in order to understand how this kind of textual resource is suitable for vehicles. Among the results, we emphasize that the emoticons promote a more casual aspect to news content and closer to the language of the readers inserted into the dynamics of online social networks.
\end{abstract}

Keywords: Emoticons, journalism, online social networks, Facebook.

\section{Introdução}

O intenso uso das tecnologias convertidas em meio tem instituído novos padrões de construção discursiva da realidade. O processo de midiatização pelo qual passa a sociedade constitui-se por atravessamento de lógicas e protocolos midiáticos que afetam campos sociais, sujeitos e ações reformulando lógicas de contato, estabelecendo novos vínculos entre a instância da produção e a instância da recepção. Nesse contexto, o campo do jornalismo é afetado pelos efeitos das dinâmicas interativas emergentes das mídias digitais, levando-o a construir e ofertar estratégias de contato com seus leitores distintas dos modelos tradicionais.

O emoticon ${ }^{2}$ é uma forma de comunicação paralinguística e sua palavra é derivada da junção dos seguintes termos em inglês: emotion (emoção) + icon (ícone). Trata-se de imagens que buscam traduzir emoções/sensações, o que a linguagem verbal não permite. As apropriações tornaram-se mais evidentes em conversações entre usuários, ganhando

\footnotetext{
${ }^{1}$ Pós-doutor em Comunicação (UFSM). E-mail: carlos_sanchotene@yahoo.com.br

${ }^{2} \mathrm{O}$ primeiro registro do uso de caracteres de texto para representar emoção ocorreu no jornal New York Herald Tribune em março de 1953, página 20, colunas 4-6. Tratou-se de uma propaganda do filme Lili estrelado por Leslie Caron. Nos meios eletrônicos, os emoticons foram utilizados pela primeira vez em setembro de 1982 pelo professor Scott Fahlman (Pittsburgh, EUA) em um fórum virtual da Universidade Carnegie Mellon (Fonte: Wikipedia. Disponível em: http://pt.wikipedia.org/wiki/Emoticon. Acesso em: 22 de dez. 2014).
} 
notoriedade na internet, principalmente, por meio do MSN Messenger ${ }^{3}$. No entanto, há uma nítida apropriação desses usos por parte do campo jornalístico, em especial, nas fanpages de jornais noticiosos.

Com o intuito de estudar esse tipo de linguagem, observamos o uso de emoticons nas fanpages dos jornais Folha de S.Paulo e Estadão ${ }^{4}$. Ambos os veículos foram escolhidos por serem referências no cenário brasileiro. Ao mesmo tempo, constituem-se como periódicos com raízes locais/regionais que, em processo de desterritorialização, experimentam um alargamento e consolidação de suas posições no contexto nacional. Além disso, dispõem de recursos e condições tecnológicas muito semelhantes. Assim, uma análise comparativa entre esses jornais afigura-se como claramente geradora de subsídios potenciais para, efetivamente, dar conta da demanda proposta.

Primeiramente, realizamos uma contextualização teórica sobre o jornalismo no cenário das redes sociais digitais. Em seguida, apresentamos a (re)invenção social dos dispositivos interacionais e uma breve entrevista com os editores de mídias digitais de ambos os jornais. Logo, apresentamos os procedimentos metodológicos e análise. Entre os resultados, concluímos que o uso de emoticons dá um tom mais informal à narrativa e compreende uma prática que acaba dando forma tendencial à composição da notícia em redes sociais digitais.

\section{Jornalismo e redes sociais digitais}

As redes digitais alteraram a esfera global das notícias e as práticas jornalísticas, atualmente, envolvendo um número maior de produtores e distribuidores de notícias, sendo que uma importante parcela destes não faz parte de organizações jornalísticas. Para Ansgard Heinrich (2011), o sistema jornalístico linear e centralizado, característico do século XX, deu lugar a um modelo não linear e descentralizado do processo noticioso. Heinrich (2011) explica que cada um dos participantes da rede representa um nó em uma densa rede de informações e a conexão interativa entre esses nós é chamado pela autora de "jornalismo em rede".

\footnotetext{
${ }^{3}$ Foi um programa de mensagens instantâneas criado pela Microsoft. O serviço surgiu em 1999, permitindo a conversação instantânea entre pessoas pela internet.

${ }^{4}$ Essa análise faz parte de um recorte de uma pesquisa mais ampla (SANCHOTENE, 2015) em que se analisou as estratégias de contato na construção do leitor nas fanpages de Folha de S.Paulo e Estadão no Facebook. 
Jornalismo em rede é o conceito estrutural subjacente que se refere à organização estrutural e as conexões não apenas dentro de uma forma de jornalismo (por exemplo, impresso ou on-line), mas para os modos de conexão emergentes dentro de toda a esfera do trabalho jornalístico. A tecnologia digital aumenta as opções de coleta de notícias, muda os modos de produção e impactos das notícias disseminando não só para a mídia on-line, mas para todas as plataformas jornalísticas que operam dentro da sociedade em rede. Nessa sociedade em rede, novos modos de conexão e fluxos de informação, então, influenciam a organização estrutural desde bancas jornalísticas até o trabalho do dia-a-dia de coleta, produção e divulgação de notícias dentro de uma esfera de rede global ${ }^{5}$ (HEINRICH, 2011: 61, tradução nossa).

A respeito dessa visada, as proposições da autora avançam no sentido que trabalhos anteriores relacionavam jornalismo em rede à interação entre participação dos cidadãos e ação jornalística; rearticulação das relações de trabalho devido as tecnologias digitais. Para Heinrich, jornalismo em rede vai além, e deve ser pensado em suas implicações estruturais, de modo que as organizações de mídia sofrem grandes transformações ao operarem em uma rede global, onde cada veículo representa um nó dentro dessa malha interconectada.

Segundo a autora, os pontos de conexão dentro da esfera do jornalismo em rede são organizados em uma forma descentralizada e mais abundante, com informações que são "jogadas" ou "retiradas" do usuário ativo. Exemplos dessa transformação podem ser ilustrados como o ocorrido em 2010, quando um jovem de 17 anos se tornou repórter em tempo real dos conflitos no Conjunto de Favelas do Alemão, no Rio de Janeiro. Cada passo da operação foi postado no Twitter "Voz da Comunidade" que, em dois dias, passou de 180 seguidores para 22 mil. Em 2011, as redes sociais também tiveram um papel importante nos movimentos de resistência à ditadura no Egito levando uma multidão às ruas. Páginas no Facebook foram usadas para informar e o governo daquele país ordenava que a internet fosse desligada pelos provedores; após 24 horas, era a vez de os celulares ficarem indisponíveis. Em 2013, os manifestos no Brasil tiveram grande repercussão em redes sociais online como

\footnotetext{
${ }^{5}$ Texto original: "Network journalism is the underlying structural concept that refers to the structural organization and the connections not just within one form of journalism (e.g., print or online), but to the emerging connection modes within the whole sphere of journalistic work as such. Digital technology enhances the options of news gathering, changes production modes and impacts news dissemination not only for online media, but for every single journalistic platform that operates within the network society. Within this network society, new connection modes and information flows then influence the structural organization of journalistic outlets just as well as the day-to-day work of gathering, producing and disseminating news within a global network sphere" (HEINRICH, 2011: 61).

${ }^{6}$ Ferramenta de microblog na qual usuários - por meio dos seus perfis - interagem através de mensagens de até 140 caracteres.
} 
Instagram $^{7}$, Twitter e Facebook funcionaram como ferramentas para troca de informações, marcação de encontros e manifestações, e principalmente, como canal de debates. Ou seja, sem essas ações e dispositivos interacionais o conhecimento sobre tais acontecimentos seria diferente.

André Lemos (2009) ao refletir sobre a nova paisagem comunicacional vai explicar que, neste começo de século XXI, temos um sistema infocomunicacional mais complexo, onde formatos massivos e pós-massivos convivem juntos. Para o autor, o novo contexto faz emergir outra esfera onde a emissão não é controlada.

\begin{abstract}
A nova esfera conversacional se caracteriza por instrumentos de comunicação que desempenham funções pós-massivas (liberação do pólo da emissão, conexão mundial, distribuição livre e produção de conteúdo sem ter que pedir concessão ao Estado), de ordem mais comunicacional do que informacional (mais próxima do "mundo da vida" do que do "sistema"), alicerçada na troca livre de informação, na produção e distribuição de conteúdos diversos, instituindo uma conversação que, mesmo sendo planetária, reforça dimensões locais (LEMOS, 2009: 03).
\end{abstract}

Sendo assim, com as possibilidades do fazer jornalístico em redes sociais online, a conversação torna-se potencializada e engendrada por uma dinâmica que envolve atores sociais (empresas jornalísticas e leitores) atuando de forma descentralizada, colaborativa e participativa. É importante sinalizar que, embora os canais de comunicação com o público sempre tenham existido, eles eram tímidos antes da consolidação da rede mundial de computadores e caracterizavam-se pelo fluxo "um-todos" da informação para as massas (LEMOS, 2009). O que temos agora, por exemplo, com celulares conectados à internet e câmeras portáteis mais acessíveis, é o uso de ferramentas que permitem o feedback do leitor simultaneamente ao processo de edição jornalística. O protagonismo do leitor e sua conectividade constante, portanto, é um dos fatores que levaram os jornais de referência a "investir" no universo das redes sociais online, desenvolvendo estratégias que visam garantir visibilidade, legitimidade, manutenção e atração de leitores.

Recuero (2009) discute algumas intersecções dos processos de difusão de informações nas redes sociais online e as práticas do jornalismo a partir de três relações: a) redes sociais como fontes produtoras de informação; b) redes sociais como filtros de informações e c) redes sociais como espaços de reverberação dessas informações. Sobre o primeiro aspecto, sabemos

\footnotetext{
${ }^{7}$ Rede social de fotos em que é possível tirar fotos com o celular, aplicar efeitos nas imagens e compartilhar com a rede de amigos e seguidores.
} 
que nas redes sociais online é possível encontrar especialistas que auxiliam na construção de pautas, assim como informações em primeira mão. Os pontos negativos, conforme a autora seriam a avalanche de informações e a falta de credibilidade. "As informações difundidas pelas redes sociais não precisam, necessariamente, ter um valor-notícia ou um compromisso social, como teoricamente, as jornalísticas (ou aquelas produzidas pelos veículos) precisam" (RECUERO, 2009: 12). Nesse sentido, qualquer indivíduo pode ser uma potencial fonte para o jornalismo, cabendo ao profissional estabelecer critérios que avaliem a credibilidade das fontes.

As redes sociais digitais também atuam como filtragem de informações, de forma a coletar e republicar as informações obtidas através de veículos informativos ou mesmo de forma a coletar e a republicar informações observadas dentro da própria rede. Estes são os casos mais comumente observados em termos de difusão de informações (RECUERO, 2009). É o caso, por exemplo, dos "retweets" no Twitter e do "compartilhar" no Facebook, por exemplo. Ambos os procedimentos acontecem quando alguém republica no sistema uma informação originalmente publicada por outra pessoa/perfil/organização jornalística.

Tais práticas, segundo Recuero, são mais claramente relacionadas com o capital social tanto na perspectiva de gerar reputação quanto de gerar outras formas de capital social. "Ao repassar informações que foram publicadas por veículos, os atores estão dando credibilidade ao veículo e tomando parte dessa credibilidade para si, pelo espalhamento da informação (RECUERO, 2009: 09)”. Nesse sentido, o valor da circulação da notícia torna-se potencializado na medida em que o público age como filtro, reverberando conteúdos.

Conforme Jenkins, Ford \& Green (2013), vivemos em uma sociedade em que a cultura dos indivíduos é marcada pela coletividade, conexão, colaboração, participação e "espalhamento" de conteúdos e se o conteúdo não circular, ele está morto. Estes autores, ao refletirem sobre o termo "cultura participativa" na contemporaneidade, a definem como a "uma diversidade de grupos que dispõe de produção e distribuição da mídia para servir a interesses coletivos"8 (JENKINS; FORD \& GREEN, 2013: 02, tradução nossa). Temos, portanto, um modelo de cultura mais participativo em que o público consumidor atua como produtor e filtro distribuidor de conteúdo. Isso porque dispõem de ferramentas que permitem o envolvimento das pessoas, ao mesmo tempo em que elas querem compartilhar.

\footnotetext{
${ }^{8}$ Texto original: "A range of different groups deploying media production and distribution to serve their collective interests" (JENKINS; FORD \& GREEN, 2013: 02).
} 
Porém, os autores chamam atenção para o fato de que as pessoas não estão compartilhando apenas por conta das possibilidades oferecidas pelas novas tecnologias, mas sim porque já faziam pessoalmente:

Enquanto as novas ferramentas têm proliferado a maneira pela qual as pessoas podem difundir materiais, fazer recomendações boca a boca e partilhar conteúdos midiáticos é um impulso que há muito tempo conduz a forma como as pessoas interagem umas com as outras. Talvez nada seja mais humano do que compartilhar histórias (...) $)^{9}$ (JENKINS; FORD; GREEN, 2013: 02-03, tradução nossa).

Assim, as redes sociais online constituem-se como novos espaços de circulação, recirculação e discussão de informações, onde as notícias, por exemplo, são reverberadas (RECUERO, 2009). Podemos ver essas reverberações no item "trending topics" do Twitter, ou nos "comentários" do Facebook, por exemplo. Tais ferramentas permitem não apenas a difusão das informações, mas também o debate e a discussão em cima das mesmas. "Assim, as redes sociais filtram e reverberam informações, mas nem sempre de forma igual àquela do jornalismo" (RECUERO, 2009: 11).

\section{A (re)invenção social dos dispositivos interacionais}

Ao refletirmos sobre as redes sociais digitais e, especificamente, o jornalismo feito nesses espaços, consideramos que os episódios comunicacionais ocorrem sempre "prémoldados" pelos processos sociais mais amplos em que se desenvolvem - e que deveriam igualmente ser examinados em contexto, para não perdermos a complexidade de suas vinculações.

Braga (2010) vai explicar que o contexto mais amplo e mais geral em que podemos inscrever todo e qualquer processo interacional corresponde ao ambiente das instituições sociais - que caracterizam o "historicamente dado", no qual todo o social se elabora. Outro contexto abrangente de inscrição necessária dos processos comunicacionais é o das linguagens acionadas para a interação.

\footnotetext{
${ }^{9}$ Texto original: "While new tools have proliferated the means by which people can circulate material, word-ofmouth recommendations and the sharing of media content are impulses that have long driven how people interact with each other. Perhaps nothing is more human than sharing stories, whether by fire or by "cloud", (JENKINS; FORD; GREEN, 2013: 02-03).
} 
Ao estudarmos um processo comunicacional em instauração, aqui apreendido pelo jornalismo em redes sociais digitais, é preciso percebê-lo como um fenômeno distinto e que representa um objetivo de conhecimento fundamental.

\begin{abstract}
Estudando as mídias, estamos observando instituições e linguagens comunicacionais em vias de constituição. E este é o ângulo (ou o objeto) que solicita, para além dos aportes sociológicos ou lingüísticos, perguntas que só podem ser feitas no âmbito de uma disciplina que se volte expressamente para a compreensão dos fenômenos comunicacionais enquanto constituidores de regras institucionais através das estratégias que produzem (BRAGA, 2010: 43).
\end{abstract}

Nesse sentido, o autor sintetiza a importância dos estudos no campo da comunicação e, principalmente, a relevância de análises sobre processos comunicacionais que constituem instituições e linguagens. Para o autor, as instituições, por suas regularidades ("maneiras de fazer simbolizadas e sancionadas"), já expressam diretamente sentidos sociais. "Embora as regras sociais possam ser expressas, não são regras porque sejam ditas - e sim porque praticadas" (BRAGA, 2010: 44).

$\mathrm{Na}$ comunicação tratamos de processos constitutivos por transformação. O que é reconhecido como "instituição" é tomado frequentemente por seus aspectos formalizados (por codificação ou por longa prática) - âmbito em que as regras são dadas como estabelecidas. Para Braga (2010), parece mais produtivo focar dispositivos interacionais devido a sua diversidade e a flexibilidade, como é o caso, por exemplo, do Facebook, pois nele a invenção e a tentativa devem ser mais perceptíveis. "Os dispositivos articulam, próximos das situações de uso de códigos e normas, os processos de ordenação social e as disposições 'de linguagem' - funcionando como seu âmbito operador de interações” (BRAGA, 2010: 49).

Os dispositivos sócio-técnicos funcionam como dispositivos interacionais, caracterizando as possibilidades relacionais entre os participantes que, por sua vez, vão dando forma tendencial aos dispositivos. Dentro de um determinado dispositivo, cada episódio comunicacional segue as "regras". "Não é 'a mídia", enquanto tecnologia, veículo ou empresa, que se caracteriza como dispositivo interacional - mas sim subconjuntos de regras e práticas habituais, apenas parcialmente determinados por estas instituições abrangentes (BRAGA, 2010: 50).

Assim, podemos pensar o uso de emoticons nas fanpages de jornais de referência como uma estratégia de aproximação com o leitor, uma vez que esse tipo de linguagem passa 
a ser apropriado em um processo que desloca-se das práticas habituais dos leitores em ambientes digitais para o jornalismo.

\section{Procedimentos metodológicos}

O corpus foi selecionado levando em consideração as postagens feitas no Facebook de Folha de S.Paulo e Estadão durante dois meses, no período compreendido pelos meses de abril e maio de 2014. Ao longo desses dois meses, observamos e coletamos todas as postagens dos jornais no Facebook. Foram contabilizadas 4.832 postagens sendo que 2.630 foram da Folha de S.Paulo e 2.202 de Estadão. Realizamos, também, uma entrevista com os editores de mídias digitais de ambos os jornais. A primeira entrevista foi realizada com Gabriel Pinheiro, editor de Mídias Sociais de Estadão, e ocorreu no dia 17 de novembro de 2014, às 15h. Já em Folha de S.Paulo, a entrevista foi realizada com Ygor Salles, editor de Mídias Sociais do jornal, e ocorreu no dia 19 de novembro de 2014, às $11 \mathrm{~h}$.

\subsection{A linguagem e o uso de emoticons nas fanpages de Folha de S.Paulo e Estadão}

A fanpage de Folha de S.Paulo está disponível no endereço $<$ facebook.com/folhadesp $>$ e apresenta 5.947.381 curtidas $^{10}$. Já Estadão, está disponível em $<$ facebook.com/estadão $>$ e apresenta 3.690.724 seguidores $^{11}$. As páginas de ambos os jornais foram criadas em 2010 e, inicialmente, reproduziam as postagens feitas no Twitter. Aos poucos os jornais vão produzindo conteúdos com linguagens específicas para a rede social.

Segundo Gabriel Pinheiro, o jornal Estadão tem muitas técnicas para apresentar seus conteúdos nas redes sociais, como a escolha da foto e do título, por exemplo.

Se você perceber, o jornal em papel tem uma linguagem, o site tem uma linguagem, as redes sociais têm outra linguagem. Claro que a gente segue o mesmo norte editorial, enfim, a gente tem o DNA do Estadão nos três produtos. Mas acho que cada um tem uma linguagem própria, cada um pode abordar coisas de uma forma (Gabriel Pinheiro, editor de mídias sociais do Estadão, entrevista).

\footnotetext{
${ }^{10}$ Último acesso em 02/11/2017.

${ }^{11}$ Último acesso em 02/11/2017.
} 
Conforme o editor, o profissional tem que pensar que no formato papel há uma experiência de leitura, de disposição de informações que é diferente do Facebook. Pinheiro aposta na liberdade em relação à linguagem nas redes sociais.

\begin{abstract}
A gente tenta ser o mais coloquial possível. Dentro do nosso manual de redação, evitamos siglas difíceis (...) O nosso leitor tem entre 18 e 34 anos, então é diferente de um assinante do jornal que é que uma pessoa mais velha, público A e B. A gente sempre toma algum cuidado, mastiga aquilo ao máximo. A gente é o mais didático possível e sempre parte do entendimento de que o leitor, principalmente em redes sociais, tem que ser o mais mastigadinho, o mais claro. Não dá pra você fazer um título muito rebuscado. O Caderno 2 tem ensaios incríveis de literatura, mas se eu transpor aquilo na rede social não vai acontecer. Então, tem um jornalista de redes sociais que sabe a nossa fórmula e ele transpõe aquilo nas redes sociais com outro título, com uma outra pegada e aquilo acontece (...) A gente pega uma frase de uma entrevista que não é o título da matéria e puxa isso pra uma outra frase, pra uma outra foto, e aquilo acontece nas redes sociais porque a gente sabe formatar de acordo com o nosso público nas redes sociais (Gabriel Pinheiro, editor de mídias sociais do Estadão, entrevista).
\end{abstract}

Gabriel Pinheiro ainda explica que os leitores que curtem a fanpage de Estadão, também curtem da Folha de S.Paulo e, geralmente, quando compartilham alguma notícia de um jornal, não compartilham a mesma do outro. Nesse sentido, é fundamental ser o primeiro para marcar território.

O nosso norte é o time. Quem dá primeiro leva. Então, por exemplo, a Marta anuncia que vai sair do PT, se a Folha de São Paulo deu isso agora, e o Estadão dá cinco minutos depois, geralmente, quem curtiu, não curte o outro. Quem curte a nossa fanpage, curte a fanpage deles. Se você já compartilhou isso via Folha, você não vai compartilhar via Estadão, a não ser que o Estadão traga uma notícia, algum enfoque diferente (...) Aconteceu uma coisa agora, por exemplo, Dilma demite um ministro. Nós já temos essa informação aqui confirmada, a gente não tem a notícia ainda e o que a gente faz? A gente coloca foto. Dilma anuncia a demissão de fulano de tal e ponto. Aguarde mais informações. Depois nós damos a notícia, a gente vai lá e edita o link, coloca urgente caixa alta. Começou aqui no Estadão. Dá a notícia e ponto, aguarde mais informações porque aquilo já vai ser super compartilhado. Quando você editar e colocar o teu link ali, aquilo já vai tá disseminado nas redes sociais, então, por isso que é importante pra você marcar território, pra você marcar o teu referencial, você tem que dar primeiro (Gabriel Pinheiro, editor de mídias sociais do Estadão, entrevista).

Nas redes sociais, percebe-se um investimento das empresas jornalísticas no que diz respeito aos modos de uso e recursos textuais utilizados, por exemplo. Todavia este é um processo que ainda está em constante transformação. Com relação aos emoticons, acreditamos que eles fazem parte do "não-dito" (ECO, 1987), e dependem do reconhecimento do leitor 
para uma possível significação, que pode ser múltipla de acordo com suas vivências, culturas e mediações (MARTÍN-BARBERO, 2008). Os emoticons são uma das formas de construir esse modo peculiar de dizer, uma das matérias significantes (a linguagem propriamente dita, o corpo, a imagem etc.) daquilo que Verón (2005) chama de constituintes do contrato de leitura.

A apropriação desses signos pelos jornais representa uma modificação na linguagem tradicional, já que atuam na superfície discursiva promovendo uma informalidade ao conteúdo publicado. No período analisado (abril e maio de 2014), verificamos a presença de seis postagens com emoticons em Estadão e sete em Folha de S. Paulo. A seguir, ilustramos alguns exemplos.

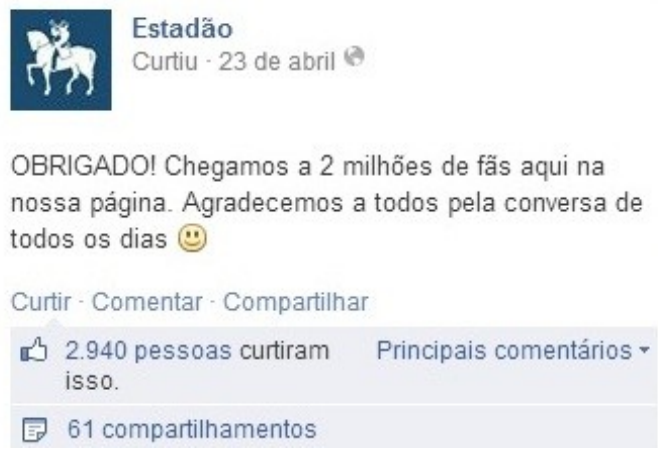

Figura 1: Post com emoticon de contentamento

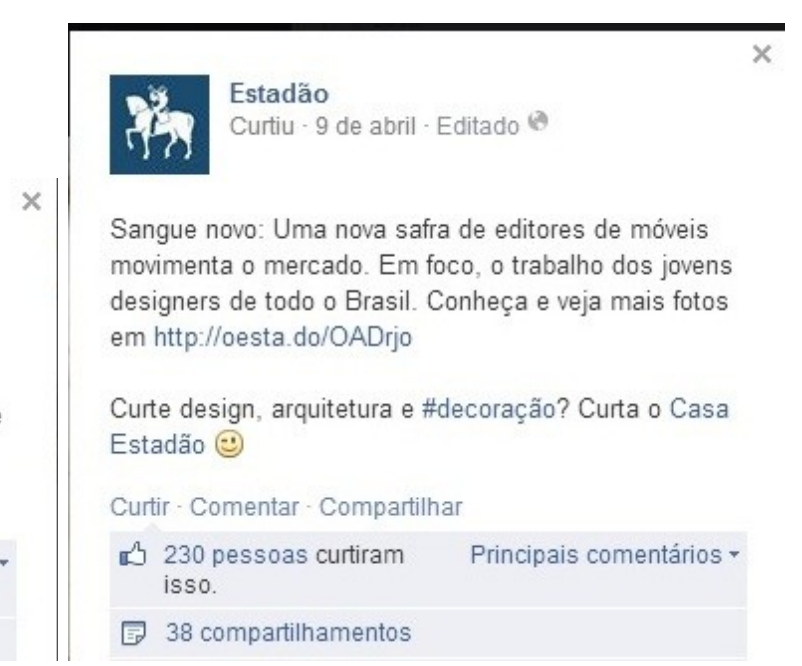

Figura 2: Emoticon com "piscar" de olhos

$\mathrm{Na}$ figura 1, Estadão utiliza um emoticon que expressa contentamento pela marca de dois milhões de seguidores em sua fanpage. Neste caso, chama atenção para o próprio dispositivo em um processo de autorreferencialidade. Assim, agradece seus leitores/seguidores em uma estratégia que pode sinalizar a alegria pelo firmamento de uma parceria. Denota, ainda, a credibilidade e confiança depositada no veículo jornalístico, bem como legitima seu espaço de circulação da informação. Já na figura 2, o emoticon com um "piscar" de olhos é usado para cumprir a função de direcionar o leitor tanto para o site para visualizar mais fotos como para a fanpage "Casa Estadão". Desse modo, amplia seus vínculos com o leitor ao direcioná-lo para outra editoria do veículo. 
Veja galeria de imagens marcantes de Gabriel García Márquez, um dos principais nomes da literatura latinoamericana no século 20 , que morreu hoje aos 87 anos: http://uol.com/bgdBWy

(:)

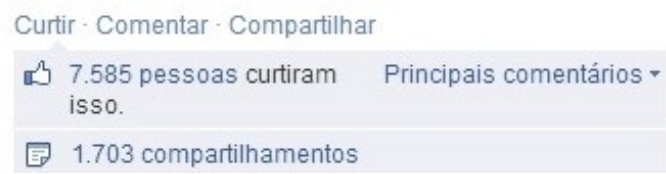

Figura 3: Emoticon que denota tristeza

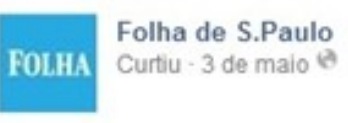

Gêmeas britânicas separadas aos cinco meses se reencontram após 78 anos. http//folha.com/no1449046

Curtir - Comentar - Compartilhar

c 6.362 pessoas curtiram isso.

293 compartilhamentos

Figura 4: Coração como exemplo de emoticon

Na figura 3, Folha de S.Paulo utiliza um emoticon sinalizando tristeza já que a notícia refere-se à morte do escritor Gabriel García Márquez. Assim, acompanha o tom da notícia despertando comoção dos leitores, e ao mesmo tempo, convocando-os para sua galeria de imagens. Na figura 4, o jornal utiliza um coração como emoticon, o que denota amor/carinho. Trata-se de um sentimento de afetividade tanto com o conteúdo da notícia como com o leitor, já que trata do reencontro de irmãs gêmeas após 78 anos. Desse modo, o jornal adota uma forma de contato mais descontraída e, ao mesmo tempo, "sensível" e "humano" em relação à narração do acontecimento.

Os exemplos acima mostrados revelam que os emoticons podem ser associados ao contexto do conteúdo jornalístico e que, talvez, estejam relacionadas aos sentimentos expressos por eles. Desse modo revelam que o texto jornalístico passa por modificações estruturais, muitas vezes associado às práticas que emergem das interações sociais (BRAGA, 2010). Nesse sentido, Borelli e Jordão (2014) vão explicar que a pretensa objetividade, a formalidade, e lides (ou leads) eram padrões para a constituição de uma linguagem jornalística, mas com a transposição para o ambiente online houve a incorporação de novos sentidos ou mesmo reformulação de padrões existentes.

Assim, os emoticons passam a compor a linguagem jornalística atuando na superfície discursiva. Ao mesmo tempo "promovem uma informalidade ao conteúdo apresentado, podendo colocar em cheque a credibilidade da informação oferecida e a legitimidade da profissão" (BORELLI, JORDÃO, 2014, p. 16). 
Desse modo, percebemos uma certa humanização dos veículos jornalísticos e uma espécie de dramatização que ocorre em distintos níveis como, por exemplo, contentamento, alegria e tristeza. Acreditamos que esse tipo de prática, além de aproximar o leitor do jornal, amplia as possibilidades de compartilhamento, pois o jornalista passa a compreender o lado humano da narrativa.

\section{Nota conclusiva}

O uso de emoticons nas lógicas de produção da notícia em redes sociais digitais está submetido aos modos como acontecem as interações no ambiente digital sendo, aos poucos, articuladas e apropriadas às narrativas dos jornais. Nos casos ilustrados, os efeitos de reconhecimento são imediatos já que representam uma linguagem universal. Seus usos ainda são pouco explorados e difundidos, mas indicam caminhos em que a linguagem jornalística dá espaço para novas formas de comunicação, promovendo um aspecto mais informal ao conteúdo apresentado e mais próximo da linguagem dos leitores inseridos nas dinâmicas das redes sociais digitais.

Os emoticons adquirem um significado já reconhecido pelos leitores em rede sociais digitais por ter sido incorporado ao ambiente digital e, como símbolo, institucionalizado (BRAGA, 2010) como uma convenção interna do funcionamento das redes. Desse modo, configuram-se como uma das estratégias linguísticas que decodificam tendências digitais, novos textos, novas lógicas estruturais moldadas por site de relacionamento e redes de compartilhamento incorporadas às dinâmicas de produção jornalística. A inserção de emoticons para a composição das notícias deve ser incluída, portanto, em um contexto a partir do qual um determinado procedimento de trabalho ganha uma legitimidade dotada pelo grupo profissional mais amplo e, por conseguinte, transborda para a narrativa jornalística sob a forma de um código padrão de narração (CASADEI, 2013).

Ao representar esses símbolos característicos das redes sociais digitais nas notícias das postagens, os jornais incorporam as narrativas das redes para as narrativas do jornal. Assim, tornam-se parte da rotina das editorias dos jornais. Deste modo, corroboramos com Casadei (2013) ao afirmar que as mudanças formais na narrativa jornalística nem sempre obedecem a regras sancionadas institucionalmente, estando ligadas, muitas vezes, a sistemas de escrita tão 
amplamente utilizados que se tornaram padrões, mesmo que não reconhecidos oficialmente por qualquer organização ou expostas em algum livro escrito. $\mathrm{O}$ uso das emoticons, por exemplo, está implicado neste mecanismo, a partir do qual as estratégias discursivas utilizadas por jornalistas seguem determinados modos padrões de narração que instauram códigos de reconhecimento socialmente compartilhados. Ou seja, são essas práticas habituais que acabam dando forma tendencial à composição da notícia em redes sociais digitais e aos poucos vão sendo institucionalizadas (BRAGA, 2010).

\section{Referências}

BORELLI, Viviane; JORDÃO, Francieli. O Uso de "Emotions" no Facebook do Jornal Gaúcho Diário de Santa Maria. In: $12^{\circ}$ Encontro Nacional de Pesquisadores em Jornalismo Santa Cruz do Sul - UNISC - Novembro de 2014.

BRAGA, José Luiz. Comunicação é aquilo que transforma linguagens. In: Revista Alceu, v. 10 - n.20 - p. 41 a 54 - jan./jun. 2010.

CASADEI, Eliza Bachega. A legitimação das redes sociais como fonte para o jornalismo sob a perspectiva dos códigos padrões de narração. Revista Ação Midiática - Estudos em Comunicação, Sociedade e Cultura. Vol. 2, No 5, 2013.

ECO, Umberto. Lector in Fabula. São Paulo: Perspectiva, 1987.

HEINRICH, A. Network Journalism. New York: Routledge, 2011.

JENKINS, Henry; FORD, Sam; GREEN, Joshua. Spreadable Media: Creating Value and Meaning in a Networked Culture (Postmillennial Pop). NYU Press. 2013.

LEMOS, André. Nova esfera Conversacional. In: Dimas A. Künsch, D.A, da Silveira, S.A., et AL. Esfera pública, redes e jornalismo. Rio de Janeiro: Editora. E-Papers, 2009.

MARTÍN-BARBERO, Jesús. Dos Meios às Mediações. Comunicação, cultura e hegemonia. Rio de Janeiro: Editora da UFRJ, 2008.

RECUERO, Raquel. Redes sociais na Internet, difusão de informação e jornalismo: elementos para discussão. In: SOSTER, Demétrio; SILVA, Fernando Firmino da. (Orgs.). Metamorfoses jornalísticas 2: a reconfiguração da forma. Santa Cruz do Sul: EDUNISC, 2009.

SANCHOTENE, Carlos. Estratégias de contato na construção do leitor coprodutor nas fanpages de Folha de S.Paulo e Estadão no Facebook. Tese (doutorado) - Pós-graduação 
em Comunicação e Cultura Contemporâneas, Faculdade de Comunicação, Universidade Federal da Bahia, 2015.

VERÓN, Eliseo. Fragmentos de um Tecido. São Leopoldo - RS: Editora Unisinos, 2005. 